\title{
POR UMA EDUCAÇÃO LATINO-AMERICANA EM DIREITOS HUMANOS: PENSAMENTO JURÍDICO CRÍTICO CONTRA-HEGEMÔNICO ${ }^{1}$
}

\author{
FOR A LATIN AMERICAN EDUCATION IN HUMAN RIGHTS: \\ CRITICAL LEGAL THOUGHT AGAINST HEGEMONICS
}

\author{
Antonio Carlos Wolkmer \\ Daniela Lippstein
}

"Soy américa Latina, un pueblo sin piernas, pero que camina" Latinoamérica - Calle 13

\section{Resumo}

O objetivo deste texto é buscar compreender os Direitos Humanos a partir de uma perspectiva crítica libertadora com base nas raízes da identidade latino-americana. A discussão justifica-se pela importância de se trazer a luz do debate jurídico crítico discursos hegemônicos de colonização travestidos como direitos humanos universais que tem legitimado práticas de dominação e negação do outro. Será adotado no desenvolvimento do trabalho um aporte metodológico indutivo que parte das premissas particulares acerca de elementos essenciais da cultura latino-americana para propor um sistema participativo e contextualizado de direitos humanos. Já quanto ao procedimento da pesquisa será adotado abordagem de teor sociológico, compreendendo que o direito é um fenômeno sócio-cultural e por essa razão busca-se o pensamento crítico latino-americano para a proposição de uma conjuntura de direitos humanos libertadora. Conclui-se com o presente estudo de que é necessário um resgate e desenvolvimento de um pensamento jurídico crítico para constituir uma educação latino-americana de direitos humanos que vise a emancipação e real efetividade dos direitos humanos superando discursos hegemônicos dominantes.

Palavras-chave: Direitos Humanos. América Latina. Filosofia da libertação. Colonialismo. Pensamento crítico. 


\section{Abstract}

The objective of this text is to seek to understand Human Rights from a liberating critical perspective based on the roots of Latin American identity. The discussion is justified by the importance of bringing in the light of the critical legal debate hegemonic discourses of colonization transplanted as universal human rights that has legitimized practices of domination and denial of the other. An inductive methodological contribution will be adopted in the development of the work that starts from the particular premises about essential elements of the Latin American culture to propose a participatory and contextualized system of human rights. Regarding the procedure of the research, a sociological-based approach will be adopted, understanding that law is a socio-cultural phenomenon and for this reason Latin American critical thinking is sought for the proposition of a liberating human rights context. It concludes with the present study that it is necessary to rescue and develop critical legal thinking to constitute a Latin American human rights education aimed at the emancipation and real effectiveness of human rights, overcoming dominant hegemonic discourses.

Keywords: Human rights. Latin America. Philosophy of liberation. Colonialism. Critical thinking.

\section{INTRODUÇÃo}

Primeiramente impõe-se descrever a tradicional educação em Direitos Humanos com base em uma matriz eurocêntrica, revelando uma política de Direitos Humanos liberal e que ignora as peculiaridades da América Latina, servindo por vezes como um discurso legitimador de violação dos próprios Direitos Humanos. Neste horizonte, privilegia-se os principais tratados e documentos internacionais de Direitos Humanos.

Na sequência pauta-se em discorrer sobre o pensamento jurídico crítico de natureza contra-hegemônica em contexto de monoculturas do saber, discorrendo sobre o pensamento latino-americano na busca por processos de descolonização.

Já no terceiro momento abordará as razões de uma educação latino-americana em Direitos Humanos como requisito para a emancipação deste continente periférico que foi amplamente explorado e colonizado, estando 
os efeitos de tal colonização presentes na vida dos latino-americanos em discursos velados de dominação.

Por sua vez, objetiva-se com o presente estudo demonstrar, a partir de crítica libertadora, a necessidade de uma educação latino-americana em Direitos Humanos como uma prática emancipadora, superando o atual modelo de educação em Direitos Humanos de tradição eurocêntrica.

Por fim, no desenvolvimento da pesquisa, será trabalhada metodologicamente a abordagem indutiva que parte das premissas particulares acerca de elementos essenciais da cultura latino-americana para propor um sistema participativo e contextualizado de direitos humanos. No que tange ao procedimento será adotado um aporte sociológico, compreendendo que o direito é um fenômeno sócio-cultural e por isso privilegia-se o pensamento crítico latino-americano para uma conjuntura de direitos humanos emancipadora.

\section{DIREITOS HUMANOS PARA OS EUROPEUS: A VISÃO EUROCÊNTRICA SOBRE A DIGNIDADE DA PESSOA HUMANA}

A presente incursão teórica abordará a forma tradicional da educação em Direitos Humanos, baseado em uma afirmação histórica centrada em instrumentos eurocêntricos e que sustentam o atual sistema internacional de Direitos Humanos.

Com a Carta Magna, em 1215, da Inglaterra deram-se as primeiras delineações de direitos escritos concedidos ao ser humano como direitos individuais. Embora o documento não fosse especificamente sobre a concessão de direitos, as disposições acerca da liberdade da Igreja em relação ao Estado, igualdade dos cidadãos perante à lei e o direito de possuir e herdar a propriedade dão os primeiros contornos dos Direitos Humanos, mas principalmente o documento foi um avanço no estabelecimento de sujeição do próprio reino às leis. Ora, com base nessa “ primeira limitação institucional dos poderes do rei, pode-se dizer que a democracia moderna desponta em embrião nesse documento do século XIII." (COMPARATO, 2015, p. 83 - 94)

Em 1679 reforça-se o instituto do Habeas corpus na Inglaterra, assegurando os direitos por meio das garantias processuais, nesse caso 
um remédio para prisões injustas ou qualquer restrição no direito de ir e vir, devendo as prisões serem justificadas (COMPARATO, 2015, p. 100). Nesse sentido:

Em matéria de direitos humanos, esse diferente método de criação do direito deu nascimento a duas linhas de tradição bem distintas: a inglesa e a francesa. Os ingleses, mais pragmáticos, consideram que o progresso na proteção jurídica da pessoa humana provém mais das garantias, sobretudo judiciais, do que das simples declarações de direitos tem sempre grande força político-pedagógica, como forma de mudança de mentalidades (COMPARATO, 2015, p. 101)

Na sequência, reconhecendo que o cidadão possuía direitos, em 1689, ainda na Inglaterra, surge a Bill of Rights, ou declaração de direitos do cidadão, que determinou a redução significativa dos poderes do monarca e ampliou os poderes do parlamento. Determinava, assim, questões sobre a estipulação de impostos, direito de petição, liberdade de eleição dos parlamentares, proibição de penas cruéis, e o reconhecimento, embora à um grupo seleto, de que não houvesse nenhum atentado à religião, aos direitos e às liberdades. Igualmente em "reafirmar alguns direitos fundamentais dos cidadãos, os quais são expressos até hoje, nos mesmos termos, pelas constituições modernas, como o direito de petição e a proibição de penas inusitadas ou cruéis" (COMPARATO, 2015, p. 108).

Em 1776, os Estados Unidos declaram independência da Grã-Bretanha, estipulando direitos individuais e direitos de revolução que vieram a influenciar a Revolução francesa mais tarde. Nessa sequência surgem a Constituição dos Estados Unidos da América (1787) e a Declaração dos Direitos (1791), essa última também conhecida como a Bill ofRights norte americana. Cumpre reforçar que a Bill ofRights norte-americana fundou-se essencialmente em direitos individuais, sendo que o pensamento político-jurídico, ainda presentemente, se mantêm individualista, "vinculado a essa fase histórica, sem aceitar a evolução posterior, no sentido de uma afirmação dos direitos sociais e dos direitos da humanidade" (COMPARATO, 2015, p. 123).

A França declara, após a queda da bastilha, a Declaração dos Direitos do Homem e do Cidadão (1789), prevendo direitos de liberdade, propriedade e segurança, principalmente de que a lei deveria ser a "expressão 
da vontade geral". Dá-se na Assembleia Nacional francesa os primeiros passos para a formulação da República francesa.

Após os horrores da Segunda Guerra Mundial, as nações reúnem-se em 1945 por um objetivo comum de proteger e promover a paz, surgindo a Organização das Nações Unidas (ONU). Em 1948, tem-se o documento mais importante em vigência até os dias atuais, a Declaração Universal dos Direitos Humanos, com 30 artigos que preveem os mais diversos direitos inerentes aos seres humanos e que devem ser reconhecidos onde quer que este se encontre. Nesse sentido afirma Piovesan que:

A internacionalização dos direitos humanos constitui, assim, um movimento extremamente recente na história, que surgiu a partir do pós-guerra, como resposta às atrocidades e aos horrores cometidos durante o nazismo. Apresentando o Estado como o grande violador de direitos humanos, a Era Hitler foi marcada pela lógica da destruição e da descartabilidade da pessoa humana, o que resultou no extermínio de onze milhões de pessoas. O legado do nazismo foi condicionar a titularidade de direitos, ou seja, a condição de sujeitos de direitos, à pertinência a determinada raça - a raça pura ariana (PIOVESAN, 2008, p. 118).

A Declaração Universal dos Direitos Humanos é hoje o eixo central do sistema universal de Direitos Humanos, seguida dos Pactos sobre Direitos Civis e Políticos e do Pacto Internacional de Direitos Econômicos, Sociais, Culturais (PIDESC). A DUDH deu início à uma legislação universal dos Direitos Humanos, passando a atribuir tais direitos à qualquer ser humano e, por conseqüência, a proteção e promoção de um novo quadro de garantias. Os pactos posteriores a declaração universal surgiram no sentido de reforço dos direitos então declarados, a exemplo o PIDESC reforçou diversos dispositivos inclusos na Declaração Universal, conforme trata os artigos 6ํㅜ e 7ํㅡ, acerca do direito ao trabalho e à justa remuneração, o art. 13 acerca do direito à educação, o art. 11 quanto direito a um nível de vida adequado quanto à moradia, vestimenta $\mathrm{e}$ alimentação e o art. 12 sobre o direito à saúde. Dentre outros, nestes dispositivos, identifica-se à garantia ao desenvolvimento, também disposto pelos principais tratados de Direitos Humanos.

Dessa forma, a Declaração Universal dos Direitos Humanos de 1948, o Pacto Internacional dos Direitos Civis e Políticos e o Pacto Internacional 
de Direitos Econômicos, Sociais e Culturais (PIDESC), ambos adotados em 1966, integram o Sistema Universal de Direitos Humanos, também conhecido como Sistema global de Direitos Humanos ou Sistema das Nações Unidas de proteção dos direitos humanos, conforme dito anteriormente.

O objetivo de tal sistema foi, a partir do pós-guerra, internacionalizar os Direitos Humanos estabelecendo interesses globais que transcendiam os interesses domésticos de cada Estado para a construção de uma proteção internacional do ser humano com fulcro no princípio da dignidade. Atualmente tal Sistema Global de Direitos humanos é constituído pela Organização das Nações Unidas (ONU), que veio em substituição da Liga das Nações com o objetivo de evitar a guerra entre os países e mediar possíveis conflitos, uma vez que tem por objetivo principal promover a paz mundial.

Contudo, o caráter universal dos Direitos Humanos enfrenta alguns paradoxos quando depara-se com princípios como a soberania dos Estados ou a autodeterminação dos povos, onde os mesmos por vezes são utilizados para legitimar violações aos Direitos Humanos. Não obstante, tal paradoxo não é o único motivo que leva à refletir sobre a universalidade dos Direitos Humanos, para tanto, Sánchez Rubio (2009, p. 24) ensina que, na própria Declaração sobre os Direitos Humanos, encontram-se desigualdades e exclusões quando, por exemplo, afirma-se que a personalidade, a cidadania e a capacidade de trabalhar, são qualidades que classificam o indivíduo com detentor ou legítimo de proteção por aquilo que se entende direitos humanos, o "todos" estende-se apenas à pessoas classificadas nessas qualidades, lhes concedendo o reconhecimento de direitos fundamentais normativamente reconhecidos.

Por essas razões, os direitos humanos compreendidos na atual conjuntura eurocêntrica não possuem caráter universal e sim relativo, pois não alcançam todos os seres humanos e sim, aqueles que correspondem a uma das três qualificações expostas anteriormente. Deste modo, mestiços, escravos, mulheres, imigrantes, dentre outros que não preenchem tais qualidades, estão condenados à exclusão e as desigualdades, porque lhes é negado a mesma identidade de uma pessoa com capacidade de trabalhar e ter cidadania. Tais critérios tem reduzido o espaço de reconhecimento de "todos" os seres humanos, separando as pessoas que possuem direitos fundamentais das que não possuem. 
Nesta seara, a visão global acerca dos direitos humanos é limitada e reducionista diante das dimensões que compreendem: normativa, jurídica e positiva. Os direitos humanos implicam, certamente, em aspectos normativos e não normativos, jurídicos e não jurídicos. Também implicam em reconhecer uma série de armadilhas: separação entre público e privado, redução do significado político, a subordinação judiciária exclusivamente ao Estado e a procedimentos formais, dentre outros. Tais armadilhas levam a consequências claras: desenvolve-se uma cultura patriarcal e machista, uma economia capitalista com a lógica de atingir o máximo de benefícios, o corte de movimentos de luta diários das distintas esferas sociais e frente as variadas formas de poder que se reduzem a uma única forma de poder e a uma única instituição, dentre outras coisas (SÁNCHEZ RUBIO, 2009, p. 118).

Não obstante, a maior questão que afronta o caráter universal dos direitos humanos são os efeitos da globalização e do pensamento neoliberal, a lógica de mercado atual, a atuação das empresas multinacionais, a posição das instituições financeiras, dentre outras, buscam um desenvolvimento estritamente econômico que não observa os direitos historicamente construídos para a proteção e bem estar do ser humano com uma vida digna. Nesse sentido, Sánchez Rubio (2010, p. 86) discorre sobre o sentido global e local da globalização e da lógica capitalista:

Por essa razão, também o sistema capitalista utiliza outro meio para sua garantia: a fragmentação daqueles grupos humanos considerados potencialmente mais perigosos para que se enfrentem entre si e não tenham uma visão total, permitindo-lhes entender os mecanismos de exclusão e manipulação social. Se por um lado se utiliza o global para impor determinada perspectiva das coisas e obrigar a todos que aceitem determinados modelos de desenvolvimento, por outro se articulam instrumentos de separação e divisão entre aqueles que saem mais prejudicados nesta repartição desigual dos bens. Daí que se faça uso de um discurso que, em função do momento, algumas vezes aposta pelo aparentemente universal e outras vezes pelo estritamente local e particular, que é origem e raiz de todo o processo de generalização posterior que se impõe. Ambas as dimensões podem, inclusive, articular-se simultaneamente. Não seria atrevimento por isso afirmar que a globalização é a outra cara da fragmentação estabelecida pelos senhores do poder. Nesse caso encontramos com um tipo de universalidade que não é fruto nem da conflitiva confluência intercultural, nem da participação dinâmica de múltiplas culturas. 
Diante disso, evidencia-se que a globalização sobrepõe valores, uma vez que, "a lógica do mercado é incompatível com a lógica dos direitos universais dos seres humanos. Aquela com o seu ideal de progresso socioeconômico é a que venceu, saindo perdedor o ideal de progresso moral" (SÁNCHEZ RUBIO, 2010, p. 87). Sendo assim, a ideologia liberal desconhece qualquer particularidade promovendo, por conseqüência, a desigualdade e exclusão social.

Para Boaventura de S. Santos existe somente um tipo de globalização, a globalização capitalista neoliberal, portanto, não há o que se falar em globalização hegemônica ou contra hegemônica, para justificar um lado positivo da globalização, este lado simplesmente não existe (SANTOS, 2011, p. 72). Não obstante, as implicações da atual globalização econômica hegemônica são pautadas da seguinte forma:

Os compromissos entre o capital e o trabalho são vulnerabilizados pela nova inserção na economia internacional (mercados livres e procura global de investimentos directos); a segurança da relação social é convertida em rigidez da relação salarial; a prioridade dada aos mercados financeiros bloqueia a distribuição de rendimentos e exige a redução das despesas públicas em material social; a transformação do trabalho num recurso global é feita de modo a coexistir com a diferenciação de salários e de preços; o aumento da mobilidade do capital faz com que a fiscalidade passe a incidir sobre rendimento imóveis (sobretudo os do trabalho); o papel redistributivo das políticas sociais decresce e; em consequência, aumentam as desigualdades sociais; a proteção social é sujeita a uma pressão privatizante, sobretudo no domínio das pensões de reforma dado o interesse nelas por parte dos mercados financeiros; a actividade estatal identifica-se, mas agora no sentido de incentivar o investimento, as inovações e as exportações, o sector empresarial do Estado, quando não é totalmente eliminado, é fortemente reduzido; a pauperização dos grupos sociais são consideradas efeitos inevitáveis da prosperidade da economia e podem ser minoradas por medidas compensatórias desde que que estas não perturbem o funcionamento dos mecanismos de mercado. (SANTOS, 2011, p. 79).

Posto isso, pode-se identificar que a atuação da globalização neoliberal propaga diferentes dimensões de violação aos Direitos Humanos, seja pela articulação do mercado, seja como pela desestruturação do Estado e a consequente promoção de desigualdades sociais. Nesse sentido, o caráter Universal dos Direitos Humanos precisa ser repensado se 
está realmente ao alcance de todos, ou se, diante de tais desigualdades, exclusões, divisões de classes, discursos autoritários de soberania ou autodeterminação dos povos, evidencia-se uma impotência no alcance global do Sistema Universal de Direitos Humanos.

\section{PENSAMENTO CRÍTICO E CONTRA-HEGEMÔNICO LATINO-AMERICANO}

Cumpre-se agora uma abordagem da compreensão latino-americana de direitos humanos. Buscando nas raízes da América Latina a história de lutas, reivindicações e conquistas de direitos, pelo reconhecimento de identidade, de pertencimento, de culturas e de tudo aquilo que define o povo latino-americano na sua mais complexa diversidade. Ao refletir sobre escritos de José Martí, em Políticas de Nuestra América, Rosillo Martínez adverte:

[...] podemos afirmar que injértese en nuestro continente los derechos humanos pero la raíz debe ser nuestra historia, nuestras luchas de liberación y las formas propias de promover la dignidad humana. Es importante recrear una tradición donde derechos humanos no sean una mera mercadería importada y ajena a las necesidades y a las preocupaciones de los hombres y mujeres latinoamericanos. Cuando los estados de América Latina predican derechos humanos, estos no deben ser una máscara, un disfraz conformado por elementos europeos, sino una construcción desde abajo, desde los pueblos. La aportación de las luchas de liberación latinoamericanas a derechos humanos debe ser mucho más que un mero "eco" $y$, por supuesto, mucho menos un eco deformado y malinterpretado; no se debe buscar tan sólo que la América practique lo que piensa la Europa, por usar la famosa frase de Alberdi (ROSILLO MARTÍNEZ, 2011, p. 16).

Dessa afirmação, aponta-se a linha de direção do presente estudo. Considerar os processos de luta e de conquistas da América Latina, enquanto história das ideias, realizando um caráter ideológico, reescrevendo a concepção clássica dos Direitos Humanos.

Viver um discurso ideológico que não pertence a América Latina a título de Direitos Humanos universais é admitir a subalternidade e a perpetuação da colonização. Isso porque, mais que a colonização de terras, recursos, pessoas e bens, está a se colonizar o pensamento. Eis que nesse 
contexto, ergue-se a bandeira do pensamento crítico, um pensamento latino-americano livre, contra-hegemônico "que surja de espaços dependentes e sonegados torna-se manifestação apta a instrumentalizar a força de uma crítica inconformista e transgressora no sentido de contribuir na desconstrução das velhas práticas de saber e de poder dominantes" (WOLKMER, 2015, p. 245)

Na contramão desse entendimento, a filosofia jurídica hegemônica busca resgatar apenas uma parte da história, impondo como uma totalidade e verdade universal, essa é a lógica da monocultura do saber da ciência ocidental, em que apenas uma razão é válida e legítima. Essa lógica é aplicada para a compreensão dos Direitos Humanos, que, atualmente, baseia-se apenas em documentos do hemisfério norte, perdendo-se uma matriz histórica universal para reconhecer apenas uma categoria ética, a eurocêntrica. Nesse sentido, "las experiencias liberadoras que dependen de contextos, que se refieren a seres humanos concretos, con sus propias características sociohistóricas y culturales, son consideradas "particulares y vernáculas", y por lo tanto son despreciadas" (ROSILLO MARTÍNEZ, 2011, p. 21-22).

Nesse sentido, uma monocultura do saber é uma forma de perpetuar os processos de colonização, uma vez que "O colonialismo, forjado enquanto conceito epistêmico na época imperial, continua hoje a ser sinônimo de empobrecimento de saberes, na medida em que promove a guetização dos saberes, obliterando outras formas de conhecimento", isso para legitimar o desmerecimento do conhecimento local considerando por exemplo que "o conhecimento científico tem sido definido como paradigma do conhecimento, e o único epistemologicamente adequado, a produção do saber local consumou-se como não-saber, ou como um saber subalterno." Curiosamente, o conhecimento científico paradigmático pertence aos países nórdicos (SANTOS, et. al., 2005, p. 30). A universalidade é algo a ser ensinado pela cultura latino-americana, os povos latino-americanos têm se destacado no reconhecimento de um pluralismo jurídico ${ }^{22}$ uma vez que:

[...] as mudanças políticas e os novos processos de luta social em países latino-americanos, em particular na região andina, não apenas gerou novas Constituições que se materializaram novos sujeitos sociais, reali- 
dades plurinacionais e práticas inovadoras de justiça popular, mas também sugeriu que, dada a diversidade de culturas minoritárias e a força incontestável dos povos indígenas do continente, um novo paradigma de Constitucionalismo, que pode ser designado Constitucionalismo pluralista (WOLKMER, 2015-b, p. 245)

As formas eurocêntricas de conhecimento demonstram uma atitude colonial frente ao conhecimento, que está interligado com o processo das relações entre centro e periferia, entre relações étnico-raciais. Essa superioridade do conhecimento europeu em muitas áreas da vida humana foi crucial para a colonização do poder no mundo de forma sistêmica. Isso porque os conhecimentos do sul ou sulbaternos foram excluídos e ignorados em todos esses anos, "desde lallustración, enelsiglo XVIII, este silenciamientofue legitimado sobre laidea de que tales conocimientosrepresentaban una etapa mítica, inferior, premoderna y precientíficadelconocimiento humano" (CASTRO-GÓMEZ; GROSFOGUEL, 2007, p. 20)

Nesse contexto é que destaca-se o giro decolonial como uma abertura e liberdade do pensamento, permitindo-se reconhecer outras teorias e outras filosofias, legitimando outras formas de saber. Este é um exercício de limpeza da colonização do ser e do saber, "eldesprendimiento de la retórica de lamodernidad y de suimaginario imperial articulado enla retórica de la democracia. El pensamiento decolonial tiene como razón de ser y objetivo la decolonialidad del poder (es decir, de la matriz colonial de poder)" (MIGNOLO, 2007, p. 29 - 30).

Não obstante, a pretensão eurocêntrica de ser o único discurso legitimador do conhecimento é algo provençal e revela um projeto perverso de uma europeização do mundo com fundamentos etnocentristas. Esse projeto tem ao fim o objetivo de poder, de dominação e de exploração, são processos de colonização com outras roupagens. Nesse sentido, adverte-se

Toda democratização possível da sociedade na América Latina deve ocorrer na maioria destes países, ao mesmo tempo e no mesmo movimento histórico como uma descolonização e como uma redistribuição do poder. Em outras palavras, como uma redistribuição radical do poder. Isto se deve, primeiro, a que as 'classes sociais', na América Latina, têm "cor", qualquer "cor" que se possa encontrar em qualquer país, em qualquer momento. Isso quer dizer, definitivamente, que a classificação das pessoas não se realiza somente num âmbito do poder, a economia, por exemplo, mas em todos 
e em cada um dos âmbitos. A dominação é o requisito da exploração, e a raça é o mais eficaz instrumento de dominação que, associado à exploração, serve como classificador universal no atual padrão mundial do poder capitalista. Nos termos da questão nacional, só através desse processo de democratização da sociedade pode ser possível e finalmente exitosa a construção de um Estado-nação moderno, com todas as suas implicações, incluindo a cidadania e a representação política (QUIJANO, 2005, p. 126).

Nessa linha, a compreensão de que o sistema universal de Direitos Humanos possui uma matriz exclusivamente eurocêntrica é um discurso de dominação, ao mesmo tempo de negação de direitos, de negação do reconhecimento da história de outros povos e de outras ideias. 0 monopólio do saber como verdade real revela que jamais será efetivo um sistema de Direitos Humanos que renega a existência de uma conjuntura histórico-sociológica de outras culturas. Para tanto, "deve a crítica servir como instrumento de luta contra as visões absolutistas e excludentes que postulam o fechamento categorial do direito a qualquer contexto social, econômico e político ou cultural" (WOLKMER, 2015-a, p. 264)

Desse modo, pretende-se abordar, no momento seguinte, uma educação latino-americana em direitos humanos libertadora que reconheça a afirmação histórica e política dos seus povos.

\section{POR UMA EDUCAÇÃO LATINO-AMERICANA EM DIREITOS HUMANOS LIBERTADORA}

A abordagem realizada até o momento revela uma política de Direitos Humanos excludente, um sistema de proteção universal eurocêntrico de dominação. Em outras palavras, Direitos Humanos para o homem branco, europeu e burguês. Uma afirmação histórica que nega outras culturas de matriz asiática, africana, latino-americana, dentre outras, que revelam-se tão importantes quanto.

Para a superação dessa hegemonia acerca do discurso universal dos Direitos Humanos é preciso um pensamento jurídico crítico, transgressor, capaz de romper com velhos paradigmas colonizadores para propor uma nova ordem internacional que tenham por fim a contemplação do ser humano na sua diversidade. 
Nessa perspectiva, a base ideológica dos Direitos Humanos tal como se encontra presentemente está fadada a não efetividade, uma vez que o discurso hegemônico é incapaz de se identificar com a complexidade da diversidade. Desse modo, a efetividade dos direitos humanos, quando muito, tem se tornado realidade somente através das vias judiciais, o que aponta uma cultura de garantias pós-violações, de reparação e não de prevenção. Não se espera mais que os direitos humanos sejam efetivados antes de uma recorrência à um tribunal, banalizando e vulgarizando aquilo se entende por Direitos Humanos, tornando-os efetivos somente quando são violados, sendo uma postura contraditória. 0 ser humano deve reconhecer que possui direitos em razão de sua própria natureza, compreendendo a sua importância e construindo-os a cada dia(SÁNCHEZ RUBI0, 2009,p. 14). Sobre esse contexto alerta que,

Para uma adequada percepção crítica dos direitos humanos, torna-se primordial direcioná-los pedagogicamente em termos interculturais, ou seja, concebê-los como novos espaços de práticas sociais e novas 'manifestações de vida', fundados no 'reconhecimento da diferença e na criação de políticas sociais voltadas para a redução das desigualdades', acelerando 'a redistribuição de recursos e a inclusão'. Há de se ter em conta que os direitos humanos, engendrados no bojo de uma tradição liberal-burguesa, não estão mais centrados meramente em necessidades corporalizadas nos direitos individuais, mas inclui direitos sociais, econômicos e culturais. Certamente que, na historicidade dos direitos humanos, a discussão dos direitos das minorias e dos grupos étnicos marginalizados tem favorecido o cenário da interculturalidade como pauta e como processo de desenvolvimento da democracia em número crescente de países (WOLKMER, 2015-a, p. 266)

Perpetuando o discurso hegemônico eurocêntrico tem-se direcionado a educação em direitos humanos dia após dia com bases nessa tradição liberal-burguesa, que desconhece as populações indígenas da América Latina, desconhece igualmente, o buen-vivir, a economia solidária, o pluralismo jurídico latino-americano e nega a existência de qualquer filosofia contra-hegemônica que não reconheça a ética eurocêntrica.

Não se propõe uma exclusão ou renegar a história dos Direitos Humanos na Europa, até porque parafraseando Paulo Freire "quando a educação não é libertadora o sonho do oprimido é ser o opressor" e não é esse o objetivo que se almeja. Busca-se dentro do recorte proposto, uma 
filosofia pautada em um pensamento jurídico crítico que tenha propósito libertador partindo das raízes latino-americanas.

Nesse sentido, algumas características da América Latina devem ser consideradas para uma educação latino-americana em Direitos Humanos. Pode-se abordar por exemplo a cidadania indígena, o buen-vivir, a economia solidária, o pluralismo jurídico, dentre outras questões que apontam um início para redesenhar a educação em direitos humanos. A exemplo da cidadania indígena, característica peculiar da América Latina, que demonstra a transformação do conceito tradicional de cidadania ligada ao Estado para algo mais amplo. As reformas constitucionais da Bolívia e do Equador foram para este fim as mais importantes na definição de um modelo estatal próximo dos povos indígenas, praticamente todos os países andinos dispõem de alguma forma sobre direitos indígenas. Contudo, no Brasil, embora a Constituição Federal de 1988 tenha significado um importante avanço nessa área, ainda deixa a desejar aspectos importantes como "participação e representação política dos povos indígenas nas instâncias de poder legislativo do Estado, o reconhecimento dos seus territórios como unidades regionais autônomas, onde [...] possa exercer suas formas próprias de governança e justiça" (VERDUM, 2016, p. 86-91).

Na sequência, importa dar significado ao buen viver ou bem viver, princípio inerente à tradição cultural indígena dos Andes. Mais do que um conceito de bem-estar é um modo e filosofia de vida. 0 bem viver é um paradigma de relações entre as pessoas, acesso as liberdades públicas e privadas, as relações entre o ser humano e a natureza, dentre outras questões que envolvem a vida como um todo. A ética do bem viver é um exercício de liberdade e de alteridade, de ser livre e solidário para com a liberdade do outro. Em outras palavras, o bem-viver requer uma vida em comunidade em permanente colaboração solidária. (MANCE, 2016-a, p. 41-51)

Não obstante, frente ao empobrecimento das condições econômicas de vida, conturbação das relações sociais e exploração ambiental agressiva, há ainda que se mencionar a economia solidária que surge como resposta a tais problemas e o resgate às práticas de tradições culturais, muitas sequer registradas, que demonstram um modelo diferenciado e sustentável de economia (MANCE, 2016-b, p. 337-347). Pode-se conceituar a economia solidária com a iniciativa que: 
[...] têm em comum a igualdade de direitos, de responsabilidades e oportunidades de todos os participantes dos empreendimentos econômicos solidários, o que implica em autogestão, ou seja, a participação democrática com exercício de poder igual para todos, nas decisões, apontando para a superação da contradição entre capital e trabalho (MANCE, 2016-b, p. 338).

Neste contexto, a construção de um processo pedagógico latino-americano permite avançar na direção do pluralismo jurídico. 0 pluralismo jurídico é, sem dúvida, um aspecto imprescindível da cultura latino-americana. Reconhecer a pluralidade de sistemas é retirar as vendas de que a justiça emana de uma única fonte, aquela normativista e estatal, pautada por uma racionalidade eurocêntrica que limita a capacidade social da América Latina enquanto povos emancipados e capazes de viver e desenvolver-se culturalmente. Isso significa que um "pluralismo transformador como estratégia mais democrática de integração procura promover e estimular a participação múltipla dos segmentos populares e dos novos sujeitos individuais e coletivos" (WOLKMER, 2015-b, p. 411)

Em linhas gerais uma educação latino-americana em direitos humanas envolve o exercício da libertação e o resgate histórico das raízes da América Latina, do seu povo, das suas lutas, das suas conquistas, como fontes emancipadoras de formas autônomas de pensar sem importar ideologias eurocêntricas. Significa dizer que o pensamento jurídico crítico acerca dos direitos humanos "envolve o desafio de comprometer-se com uma práxis histórica da libertação, fundada em lutas e em sociabilidades emergentes, tornando-se permanente 'processos de construção social da realidade' (WOLKMER, 2015-a, p.267).

\section{CONCLUSÃo}

O contexto histórico eurocêntrico dos direitos humanos revela uma categoria de direitos liberal burguesa. Nesse cenário, direitos humanos são para os colonizadores e não para colonizados. Os Direitos Humanos foram fundados para o homem branco, europeu e burguês. Um discurso que contém em si uma ideologia da exclusão não pode servir para um sistema universal de direitos humanos. 
Nesse sentido, pode-se vislumbrar, a partir da literatura intelectual latino-americana e de alguns adeptos europeus à esta corrente, que as formas hegemônicas e monoculturais do saber possuem por objetivo final o monopólio do poder como instrumento para a exploração. A importação de ideologias, filosofias e modos de saber são práticas de colonização com outras roupagens das que praticadas no período imperial, mas mesmo assim com finalidades de dominação semelhantes. Essa forma de percepção ocorre com a compreensão dos Direitos Humanos enquanto única visão legítima, a visão eurocêntrica como uma verdade universal.

Para tanto, é necessário um pensamento jurídico crítico capaz de transgredir a clássica concepção dos Direitos Humanos como um processo que intenta processos de emancipação. Aproxima-se, assim, o discurso da realidade latino-americana para uma construção histórica-social pautada pelas raízes da própria identidade periférica desde o Sul.

Contudo, essa realidade só será possível a partir de uma educação latino-americana de direitos humanos, que leve em consideração o exercício de uma prática voltada para a cidadania indígena, o bem viver, a economia solidária e o pluralismo jurídico, que percorrem as constituições andinas e expressam a representação dos movimentos sociais mais autênticos da região.

Desse modo, a luta por um outro modelo de educação em direitos humanos é um dos processos necessários para uma plena filosofia da libertação que reconheça a América Latina como ator da sua própria história. Esse processo é crucial para o desenvolvimento justo de políticas sociais e da efetivação dos direitos humanos. Um sistema universal de Direitos Humanos que não reconhece, ou sequer conhece, a realidade latino-americana será sempre um sistema insuficiente e excludente, porque nele as comunidades tradicionais, o meio ambiente, as coletividades subalternas, as mulheres, os afrodescendentes, os povos indígenas, toda e qualquer minoria étnica ou racial que jamais terá o seu espaço legitimado. Apenas uma conjuntura político-jurídica emanada de seus pares é capaz de atingir um ideal de justiça social.

Por fim, uma educação latino-americana em direitos humanos saberá reconhecer as necessidades e garantias para o pleno exercício das liberdades e dos direitos a serem fundados em um pensamento crítico contra- 
-hegemônico e assegurados para uma concepção participativa de Direitos Humanos enquanto estratégia de luta para a realização da libertação.

\section{NOTAS}

1 Artigo originou-se de um paper submetido para disciplina MARCOS TEÓRICOS EM TEORIAS CRÍTICAS E DIREITO no âmbito de Pós-Graduação em Direito, Doutorado, da UFSC. Disciplina ministrada pelo Prof. Dr. Antônio Carlos Wolkmer e Profa. Dra. Lidia P. Castillo Amaya (El Salvador).

2 Para melhor aprofundamento sobre o tema ler: WOLKMER, Antônio Carlos. Pluralismo jurídico: fundamentos de uma nova cultura do direito. 4ํㅡ. Ed. São Paulo: Saraiva, 2015.

\section{REFERÊNCIAS}

CASTRO-GÓMEZ, Santiago; GROSFOGUEL, Ramón. Prólogo. Giro decolonial, teoría crítica y pensamiento heterárquico. IN: CASTRO-GÓMEZ, SANTIAGO; GROSFOGUEL, RAMÓN (Org.). El giro decolonial: reflexiones para una diversidad epistémica más allá del capitalismo global. Bogotá: Siglo del Hombre Editores; Universidad Central, Instituto de Estudios Sociales Contemporáneos y Pontificia Universidad Javeriana, Instituto Pensar, 2007.

COMPARATO, Fábio Konder. A afirmação histórica dos direitos humanos. 10 ed. São Paulo: Saraiva, 2015.

MANCE, Euclides André. Bem viver. In: SIDEKUM, Antônio; et. al. (Org.). Enciclopédia latino-americana dos direitos humanos. Blumenau: Nova Petrópolis: Nova Harmonia, 2016-a.

MANCE, Euclides André. Economia solidária. In: SIDEKUM, Antônio; et. al. (Org.). Enciclopédia latino-americana dos direitos humanos. Blumenau: Nova Petrópolis: Nova Harmonia, 2016-b.

MARTÍNEZ, Alejandro Rosillo. Derechos humanos desde el pensamiento latinoamericano de la liberación. Tesis Doctoral. Doctorado en Estudios Avanzados en Derechos Humanos. Universidad Carlos III de Madrid, 2011.

MIGNOLO, Walter D. El Pensamiento Decolonial: Desprendimiento Y Apertura: Un Manifiesto. In: CASTRO-GÓMEZ, Santiago; GROSFOGUEL, Ramón (Orgs). El giro decolonial: reflexiones para una diversidad epistémica más allá del capitalismo global. Bogotá: Siglo del Hombre Editores; Universidad Central, Instituto de Estudios Sociales Contemporáneos y Pontificia Universidad Javeriana, Instituto Pensar, 2007. 
PIOVESAN, Flávia. Direitos humanos e o direito constitucional internacional. 9 ed. rev. e. ampl. São Paulo: Saraiva, 2008.

QUIJANO, Aníbal. Colonialidade do poder, eurocentrismo e América Latina. In: Edgardo Lander (org). A colonialidade do saber: eurocentrismo e ciências sociais. Perspectivas latinoamericanas. Colección Sur Sur, CLACSO, Ciudad Autónoma de Buenos Aires, Argentina. setembro 2005. Disponibleenla World Wide Web: http://bibliotecavirtual.clacso.org.ar/

SÁNCHEZ RUBIO, David. Fazendo e desfazendo direitos humanos. Tradução de Clovis Gorczevski. Santa Cruz do Sul: Edunisc, 2010.

SÁNCHEZ RUBIO, David. Repensar los derechos humanos. De La anestesia a la sinestesia. Madrid: Mad, 2009.

SANTOS, Boaventura de Sousa; et al. Para ampliar o cânone da ciência: a diversidade epistemológica do mundo. IN: SANTOS, Boaventura de Sousa (Org.). Semear outras soluções: os caminhos da biodiversidade e dos conhecimentos rivais. Rio de Janeiro: Civilização brasileira, 2005.

SANTOS, Boaventura de Souza. Os processos da globalização. In: SANTOS, Boaventura de Souza (Org.). A globalização e as ciências sociais. 4 ed. São Paulo: Cortez, 2011.

SANTOS, Milton. Por uma outra globalização: do pensamento único à consciência universal. 6. ed. Rio de Janeiro: Record, 2001.

SIDEKUM, Antônio; et. al. [orgs]. Enciclopédia latino-americana dos direitos humanos. Blumenau: Nova Petrópolis: Nova Harmonia, 2016.

VERDUM, Ricardo. Cidadania indígena. In: SIDEKUM, Antônio; et. al. (Org.). Enciclopédia latino-americana dos direitos humanos. Blumenau: Nova Petrópolis: Nova Harmonia, 2016.

WOLKMER, Antônio Carlos. Introdução ao pensamento jurídico crítico. 9. ed. São Paulo: Saraiva, 2015-a.

WOLKMER, Antônio Carlos. Pluralismo jurídico: fundamentos de uma nova cultura do direito. 4. ed. São Paulo: Saraiva, 2015-b.

. 0 que a História tem a dizer sobre Educação em Direitos Humanos. 
In: BITTAR, Eduardo C.B. (Org.). Educação e metodologia para os direitos humanos. São Paulo: Quartier Latin, 2001, p.205-217.

Recebido em: 29-1-2017

Aprovado em: 29-5-2017

\section{Antonio Carlos Wolkmer}

Doutor em Direito e membro do Grupo de Trabalho da CLACSO (Argentina/ Equador): "Pensamiento Jurídico Crítico". Membro da Asociação Argentina de Sociologia Jurídica. É investigador nivel 1-A do CNPq e consultor Ad Hoc da CAPES. Professor do Programa de Pós-Graduação em Direito do UNILASALLE-RS e do Mestrado em Direitos Humanos da Universidade do Extremo Sul Catarinense (UNESC-SC). Professor titular aposentado no PPGD da Universidade Federal de Santa Catarina (UFSC). E-mail: acwolkmer@gmail.com

Centro Universitário La Salle - Canoas. Programa de Pós-Graduação. Av. Victor Barreto, 2288. Centro. 92010000. Canoas - RS.

\section{Daniela Lippstein}

Doutoranda em Direito pela Universidade Federal de Santa Catarina (UFSC). Mestre em Direito pela Universidade de Santa Cruz do Sul - UNISC na linha de pesquisa de Políticas Públicas de Inclusão Social com bolsa PROSUP, Tipo II, provida pela CAPES. Mestre em Direitos Humanos pela Universidade do Minho (Portugal) (Convênio Dupla Titulação UNISC-UMinho). Especialista em Direito Internacional - UNIASSELVI (Especialização Lato Sensu). Integrante do Grupo de Estudos em Desenvolvimento, Inovação e Propriedade Intelectual (GEDIPI/UNISC). Professora do Curso de Direito da Universidade Regional Integrada do Alto Uruguai e das Missões - URI Campus de Frederico Westphalen/RS. Professora e coordenadora de Pesquisa do Curso de Direito das Faculdades João Paulo II em Passo Fundo/RS. Advogada. E-mail: dlippstein@gmail.com.

Universidade Federal de Santa Catarina (UFSC). Centro de Ciências Jurídicas. Programa de Pós-Graduação em Direito.

Campus Universitário Reitor João David Ferreira Lima. Trindade. CEP 88040900. Florianópolis - SC 